\title{
A Smart Under-Frequency Load Shedding Scheme based on Takagi-Sugeno Fuzzy Inference System and Flexible Load Priority
}

\author{
J. A. Laghari ${ }^{1}$, Suhail Ahmed Almani ${ }^{2}$, \\ Department of Electrical Engineering, Quaid-e-Awam \\ University of Engineering Science \& Technology, (QUEST) \\ Nawabshah, 67480, Sindh, Pakistan
}

\author{
Jagdesh $\mathrm{Kumar}^{3}$ \\ School of Technology and Innovations, University of Vaasa, \\ Finland, \\ Department of Electrical Engineering, Quaid-e-Awam \\ University of Engineering Science \& Technology, (QUEST) \\ Nawabshah, 67480, Sindh, Pakistan
}

\author{
Hazlie Mokhlis ${ }^{4}$ \\ Department of Electrical Engineering, Faculty of \\ Engineering, University of Malaya, 50603 Kuala Lumpur, \\ Malaysia \\ Ab Halim Abu Bakar ${ }^{5}$ \\ University of Malaya Power Energy Dedicated Advanced \\ Centre (UMPEDAC), Level 4, Wisma R\&D UM, Jalan \\ Pantai Baharu, University of Malaya, 59990 Kuala Lumpur, \\ Malaysia
}

\begin{abstract}
This paper proposes a new smart under frequency load shedding (UFLS) scheme, based on Takagi-Sugeno (TS) fuzzy inference system and flexible load priority. The proposed scheme consists of two parts. First part consists of fuzzy load shed amount estimation module (FLSAEM) which uses TS-fuzzy to estimate the amount of load shed and sends its value to accurate load shedding module (ALSM) to perform accurate load shedding using flexible load priority. The performance of the proposed scheme is tested for intentional islanding case and increment of sudden load in the system. Moreover, the response of the proposed scheme is compared with adaptive UFLS scheme to highlight its advantages. The simulation results show that the proposed UFLS scheme provides the accurate load shedding due to advantage of flexible priority whereas adaptive UFLS scheme due to fixed load priority does not succeed to achieve accurate load shedding.
\end{abstract}

Keywords-Distributed generation (DG); flexible load priority; fuzzy load shed amount estimation module (FLSAEM), islanded distribution network; under-frequency load shedding (UFLS)

\section{INTRODUCTION}

The global apprehension on environmental security and deregulation in the power industry has make it inevitable to utilize the DG resources for the production of electrical energy [1]. Currently, most of DGs are operating in parallel with the utility grid to fulfil the enhanced demand of load. However, in case of islanding event, these DGs are disconnected from the grid to avoid any severe consequences. Islanding condition is a phenomenon in which distribution system is isolated from grid due to severe fault; yet continue to be supplied from the distributed generation unit connected to distribution system [2]-[4].

Islanding may cause several safety hazards issues, power quality issues, voltage and frequency stability issues during islanding. Due to the aforementioned severe consequences of islanding, it is recommended by the IEEE Std 1547 [5], and IEEE Std 929 [6] to disconnect the DG within 2 seconds from the distribution network. However, if DG is isolated from the distribution network then its full capacity will not be utilized.

Furthermore, an intentional islanding operation of distribution network may have the advantage that it can utilize the maximum capacity of DG, improve reliability of distribution system, reduce the congestion of transmission and distribution network [7]. Thus, an intentional islanding operation of a distribution system may be advantageous if various issues concerned to it are addressed satisfactorily.

When a distribution system operating at peak capacity is islanded, the frequency will go down very fast and requires an efficient load shedding technique to shed some load in order to stabilize the frequency [8]. However, despite of the development in computer and communication technologies, power system around the globe still using conventional load shedding approaches and has not changed for decades. The conventional UFLS scheme has the limitation that they shed surplus or insufficient amount of load shed. Due to this, conventional under frequency load shedding (UFLS) schemes has resulted in huge number of power blackouts around the globe. This has put question mark on the reliability of these conventional UFLS schemes [9], [10]. The use of latest advancement in computer and communication may be a good option in terms of the technical perspectives to enhance the reliability of existing huge and complicated power systems [11].

Accurate load shedding depends upon two main factors; estimation of load shed amount and accurately disconnecting that amount of load. However, most of the research trend remains in the direction of accurate estimation of load shed amount only. For accurate estimation of load shed amount, mostly power swing equation is employed. However, power 
swing equation also suffers from inaccurate estimation due to variations in rate of change of frequency (ROCOF) behavior. It has been found that ROCOF value greatly affects due to operating capacities of a power system (base load and peak load capacity), system voltage profile and load voltage characteristics [12]. The values of ROCOF are different for similar amounts of load variation at base and peak capacity. This variation in ROCOF behavior causes the inaccurate estimation of the power imbalance which leads to inaccurate load shedding [13]. In order to overcome this difficulty, a novel UFLS scheme is presented in reference [14], using the frequency second derivative as a source of information to predict the trajectory of frequency. The scheme used Newton method based approximation and the interpolation of the frequency second derivative to predict the minimum frequency value that can provide the actual load shedding. The scheme has the advantage that it sheds lesser amount of load shed and supplied most of the load to the system [14].

Further efforts to accurately estimate the load shed amount/power imbalance were the application of computational intelligence based techniques such as artificial neural network, fuzzy logic control, adaptive neuro fuzzy inference system, and genetic algorithm. However, as the accurate load shedding not only depends upon the accurate estimation of load shed amount but accurate amount of load to be disconnected is also another important factor to be considered. This resulted inaccurate load shedding in many adaptive techniques proposed in [15]-[18] and computational intelligence techniques proposed in [19]-[23] despite of accurate estimation. Though, it was proved by above researchers that adaptive and computational intelligence based UFLS schemes shed lesser amount of loads compared to traditional UFLS schemes. Nevertheless, the frequency overshoot in all of these techniques clearly indicates that these techniques have disconnected some extra loads.

The justification for accurate load shedding may be obtained if the DG frequency restores to reference value without any overshoot. This may be obtained if the loads of distribution system which are taking part in load shedding are given some flexible priority instead of fixed priority. This flexibility can be achieved if vital loads are given fixed priority and non-vital loads are given flexible priority. With this flexible load priority arrangement, the accurate amount of load can be shed by disconnecting those loads whose total value is almost equal or near to the load shed amount. This may also lead to frequency recovery without overshooting. The proposed UFLS scheme employs both factors. For accurate estimation of load shed amount, it employs Takagi-Sugeno fuzzy inference system and for accurate amount of load to shed, it employs flexible load priority.

\section{MethodOLOGY}

The proposed UFLS scheme is considered to operate and monitor distribution network after the occurrence of islanding event. It consists of two main modules:

1) Fuzzy Load Shed Amount Estimation Module
(FLSAEM)

2) Accurate Load Shedding Module (ALSM)
The explanation of these modules is presented in the following sections:

\section{A. Fuzzy Load Shed Amount Estimation Module (FLSAEM) Description}

The first module of the proposed UFLS scheme consists of fuzzy load shed amount estimation module. This module is used to estimate the accurately load shed amount during islanding, or load increment events. It uses Takagi-Sugeno fuzzy inference system. The FLSAEM has two inputs namely centre of inertial frequency and rate of change of centre of inertial frequency and one output load shed amount [24]:

FLSAEM will estimates the accurate amount of load shed between the generation and load demand using these input values. The modeling of Takagi-Sugeno fuzzy inference system comprises fuzzification, rule base inference mechanism, and defuzzification steps. Fuzzification is the process of converting crisp statements into fuzzy statements by using membership functions. The membership function of input and output are shown in Fig. 1 to 3.

The linguistic variables membership functions of input centre of inertial frequency are COF (Cut-off frequency), VELF (Very extremely low frequency), ELF (Extremely low frequency), VLF (Very low frequency), LF (Low frequency), and NF (Normal frequency).

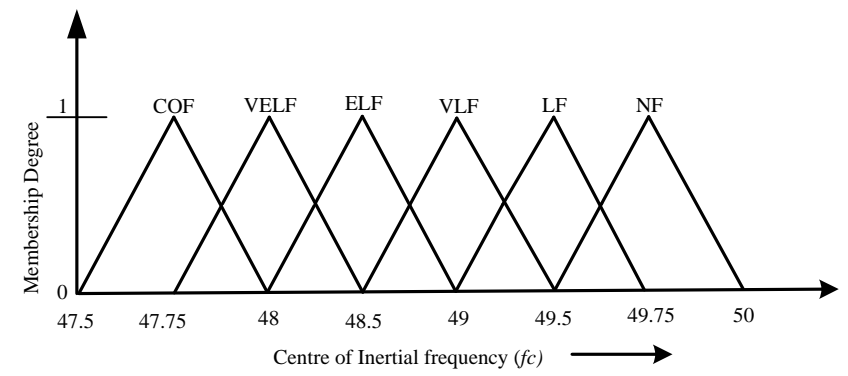

Fig. 1. Centre of inertial frequency membership functions.

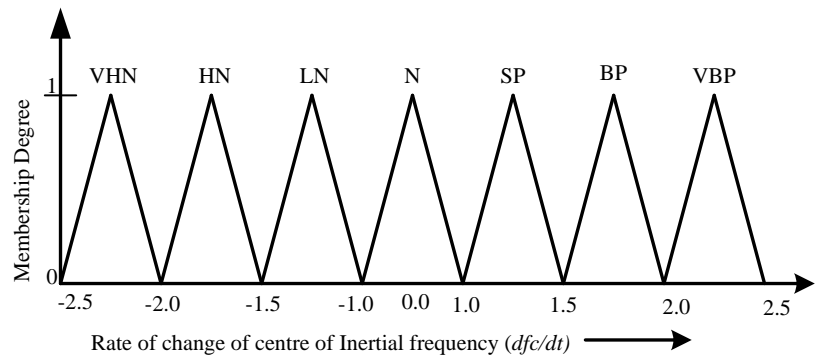

Fig. 2. Rate of change of centre of inertial frequency membership functions.

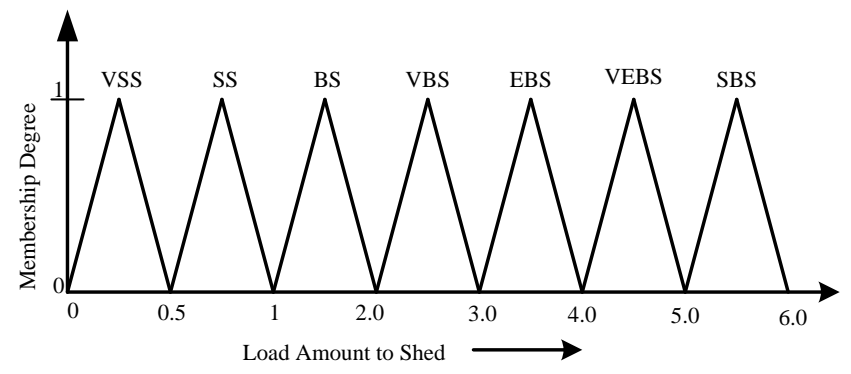

Fig. 3. Load shed amount membership functions. 
The input rate of change of centre of inertial frequency membership functions are VHN (very high negative), HN (High negative), LN (Low negative), N (normal), SP (small positive), BP (big positive), VBP (very big positive). The linguistic variables of output power imbalance are VSS (very small shed), SS (small shed), BS (big shed), VBS (Very big shed), EBS (Extremely big shed), VEBS (Very extremely big shed), SBS (Super big shed).

These fuzzified inputs are evaluated by rules through fuzzy inference mechanism and are applied in IF-THEN rule form followed by defuzzification step through weighted average method to get final real output. FLSAEM sends this value to Accurate Load Shedding Module (ALSM) via a communication link to disconnect the loads.

\section{B. Accurate Load Shedding Module}

ALSM module after receiving the load shed amount (LSA) from FLSAEM module, it will check frequency limit of 49.5 $\mathrm{Hz}$ in order to prevent the activation of load shedding schemes for smaller load variations [25]. From this step, amount of load can be shed by two ways. One way to perform load shedding is to disconnect the loads with fixed load priority. This may result in inaccurate load shedding despite of accurate estimation of power imbalance. Another way to get accurate load shedding is to disconnect the loads with random load priority. This random load priority may be able to accurately disconnect the required load and frequency may restore to its nominal value without overshoot. The proposed UFLS scheme applies the later approach to obtain the accurate load shedding. Hence, ALSM after receiving the load shed amount from FLSAEM determines the magnitudes of random priority loads. By using this information, the proposed algorithm calculates the number of possible combinations, as given by:

$$
\text { Max. No. of Combinations }=2^{N}-1
$$

where $\mathrm{N}$ shows the quantity of random loads. After this, ALSM determines the load summation and absolute error in each combination as below:

$$
\text { Error }{ }_{i}=L S A-\sum P_{i_{-} \text {combination }}
$$

where,

$(\text { Error })_{i}=$ absolute error of the $\mathrm{i}^{\text {th }}$ combination,

LSA = load shed amount,

$\sum \mathrm{P}_{\mathrm{i} \text { combination }}=$ sum of active power of $\mathrm{i}^{\text {th }}$ combination.

The combination with minimum error is selected for disconnecting the loads in order to obtain the accurate load shedding. To perform this, the proposed ALSM module sends the signals directly to the breakers of these loads in order to trip them. In case, the load shed amount is higher than the total magnitude of random priority loads, ALSM will perform load shedding in two steps. At the first step, ALSM will disconnects all random priority loads whereas in the second step, it will start disconnecting the fixed priority loads until the condition $\Delta \mathrm{P} \leq 0$ is achieved. The delay time consisting of computation, communication, and breaker operation is considered as 120 milliseconds. The flow chart of proposed UFLS scheme is shown in Fig. 4.
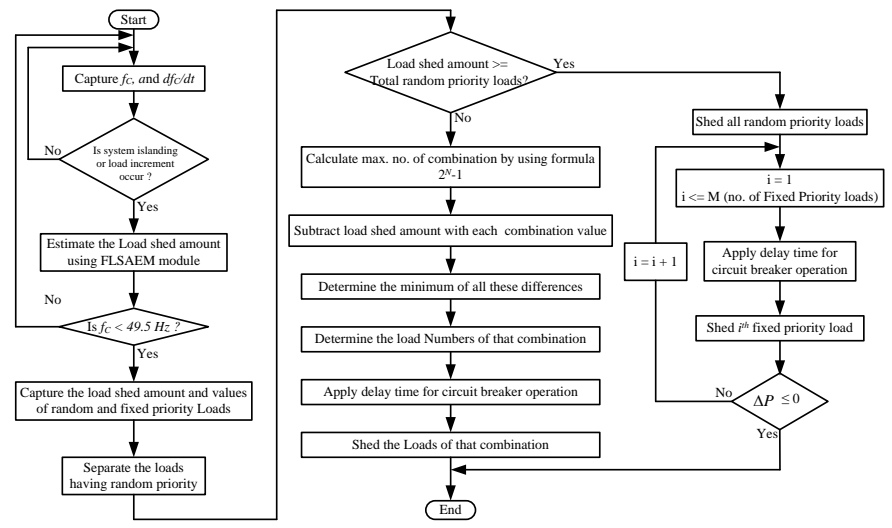

Fig. 4. Flow chart of proposed UFLS scheme.

\section{MODELING OF TEST SYSTEM AND PROPOSED UFLS SCHEME}

In this research, a 102-bus distribution network is considered to validate the proposed under-frequency load shedding scheme. The network is part of an existing Malaysia distribution network. The test system consists of 102 buses, 79 lumped loads and 9 mini-hydro generators as shown in Fig. 5.

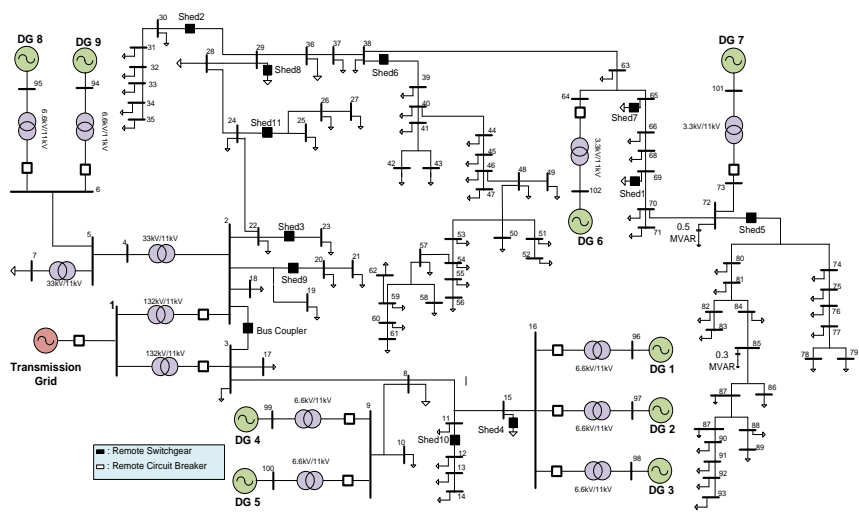

Fig. 5. 102-Buses test system.

As indicated in Fig. 5, a bus coupler's breaker for an $11 \mathrm{kV}$ network is located at the intersection of bus 2 and bus 3. To improve the voltage profile, capacitor banks with ratings 0.3MVAR and 0.5MVAR are used at buses 85 and 72 , respectively. The modeling of the various components of test system is done by using the standard models for exciter, governor, and hydraulic turbine in PSCAD/EMTDC library.

\section{A. Modeling of Proposed UFLS Scheme in Matlab and Interfacing with PSCAD}

PSCAD/EMTDC and MATLAB interface technologies are used for FLSAEM and ALSM modeling. More specifically, the Takagi-Sugeno fuzzy inference system and ALSM module are built in MATLAB and distribution system is modelled in PSCAD. This FLSAEM modeling and its interfacing with MATLAB requires three main components to perform interfacing successfully.

1) Sub routine to call for MATLAB and PSCAD interface. 
2) M-File for calling the Takagi-Sugeno fuzzy inference system.

3) MATLAB fis file which consists of Takagi-Sugeno fuzzy inference system.

To call sub routine, MATLAB block in PSCAD/EMTDC is built by creating a new component. This new MATLAB block can be developed by using a program written by the authors. The program asks for the name of the new component and number of input, output and their names. A graphical icon of the block is then automatically generated along with an empty m-file, which is opened for user input in a text editor shell. The user should then enter the appropriate MATLAB statements into this m-file. Fig. 6 shows the sub routine written in FORTRAN command for interfacing with PSCAD.

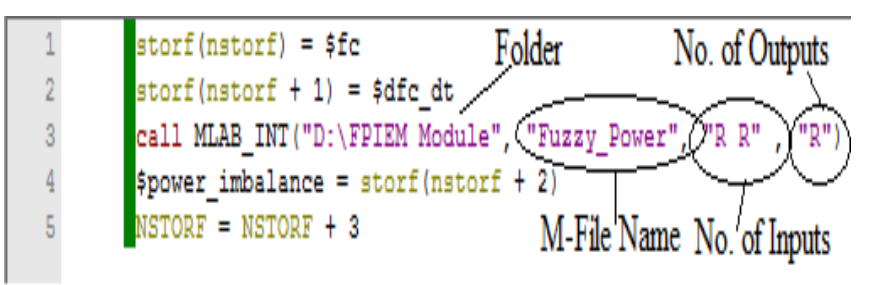

Fig. 6. Sub routine for calling MATLAB \& PSCAD interfacing.

The second step required is to write MATLAB code in MFile for calling fuzzy inference system (fis) file. Fig. 7 shows the m-file structure in which TS-fuzzy is called to estimate the power imbalance whereas Fig. 8 shows the PSCAD and Matlab interface arrangement.

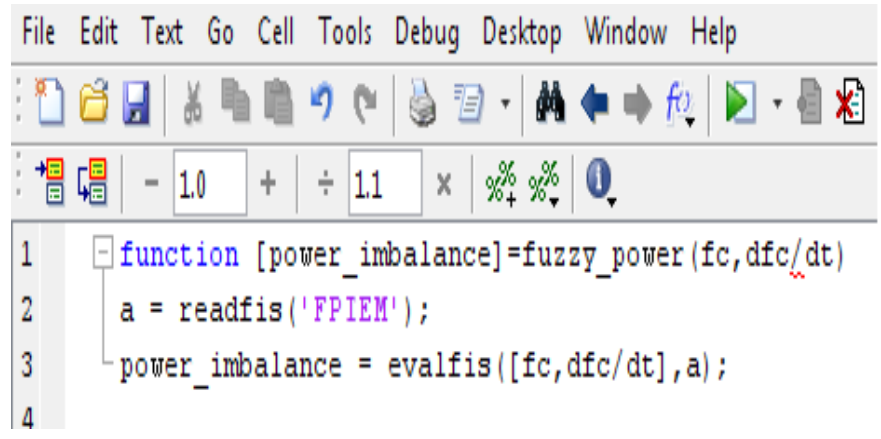

Fig. 7. M-File for calling Takagi-Sugeno inference system.

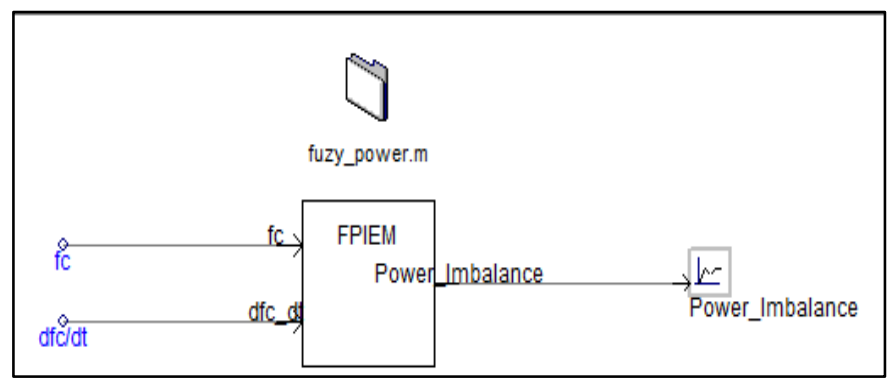

Fig. 8. New component with M-File.

In total, 11 loads in distribution system are chosen to take part in load shedding. Among these loads, load ranked 1 to 6 are given random priority and load ranked 7-11 are given fixed priority. Table I shows loads with their priority rankings.
The loads with random priority can be disconnected without following any sequence.

TABLE I. LOAD DATA WITH THEIR PRIORITY

\begin{tabular}{|l|l|l|l|l|}
\hline $\begin{array}{l}\text { Load } \\
\text { Rank }\end{array}$ & Bus No. & $\begin{array}{l}\text { Active Power } \\
\text { (MW) }\end{array}$ & $\begin{array}{l}\text { Adaptive } \\
\text { scheme } \\
\text { Priority }\end{array}$ & $\begin{array}{l}\text { Proposed } \\
\text { scheme } \\
\text { priority }\end{array}$ \\
\hline 1 & 69 & 0.1 & Fixed & Random \\
\hline 2 & $30-35$ & 0.196 & Fixed & Random \\
\hline 3 & 23 & 0.413 & Fixed & Random \\
\hline 4 & 15 & 0.71 & Fixed & Random \\
\hline 5 & $74-93$ & 0.75 & Fixed & Random \\
\hline 6 & $39-62$ & 1.35 & Fixed & Random \\
\hline 7 & 65 & 0.14 & Fixed & Fixed \\
\hline 8 & 29 & 0.153 & Fixed & Fixed \\
\hline 9 & $20-21$ & 0.21 & Fixed & Fixed \\
\hline 10 & $12-14$ & 0.37 & Fixed & Fixed \\
\hline 11 & $25-27$ & 0.55 & Fixed & Fixed \\
\hline
\end{tabular}

\section{B. Modeling of Adaptive UFLS Scheme}

To highlight the robustness of the proposed UFLS scheme, its response will be compared with adaptive UFLS scheme which employs swing equation to perform load shedding. This UFLS scheme will also initiates when the system frequency falls below the $49.5 \mathrm{~Hz}$ threshold. The overall 11 stage load shedding plan considered for proposed UFLS scheme; and adaptive scheme are shown in Table I.

\section{Simulation Results}

To demonstrate the effectiveness of proposed UFLS scheme, its response is tested for several intentional islanding, and load increment cases. Furthermore, its response is also compared with adaptive UFLS scheme to show its effectiveness. The following sections provide the detailed comparison of both schemes for different cases.

\section{A. Intentional Islanding Operation Case}

In this case, islanding operation of distribution system is simulated. For this purpose, grid breaker is disconnected at $\mathrm{t}=5 \mathrm{~s}$. The total load demand of the test system in this case is 18.7 MW from which 15.2 MW is supplied by the DG units and $3.5 \mathrm{MW}$ is supplied by the utility grid. This results in power mismatch of $3.5 \mathrm{MW}$. The test system possesses a 0.9 MW of total spinning reserve. Upon occurrence of islanding event, FLSAEM checks first frequency limit of $49.5 \mathrm{~Hz}$. After checking this, FLSAEM using frequency and rate of change of frequency measurements, estimates the load shed amount for this case and sends this amount to ALSM module. For a 3.5 MW power imbalance, the FLSAEM module determines 2.6 MW as the load shed amount. The ALSM module after receiving load shed amount, determines that among 11 loads, six loads have random priority. The maximum number of combinations for 6 random priority loads is 63 and is shown in Table II. After this, the ALSM module determines the sum and absolute error of each combination. The ALSM will select the combination with minimum error for load shedding.

Table II shows that the combination no. 50 has the minimum error (0.013). The combination number 50 consists of load ranked $1^{\text {st }}, 3^{\text {rd }}, 5^{\text {th }}$ and $6^{\text {th }}$ respectively. The proposed UFLS scheme directly sends signals to shed these loads in order to make islanding operation successful. The frequency response of all three UFLS schemes is shown in Fig. 9, 
whereas power imbalance, total amount of load shed, and other parameters of both these techniques are shown in
Table III.

TABLE II. PROCEDURE FOR FINDING LOADS OF BEST COMBINATION

\begin{tabular}{|c|c|c|c|c|c|c|c|c|c|}
\hline No. & $\begin{array}{l}\text { Variables } \\
\text { Combination }\end{array}$ & $\sum_{\text {combination }}$ & $\Delta \mathbf{P}$ & $\begin{array}{l}\text { Absolute }(\Delta \mathbf{P}- \\
\left.\sum \text { combination }\right)\end{array}$ & No. & $\begin{array}{l}\text { Variables } \\
\text { Combination }\end{array}$ & $\sum_{\text {combination }}$ & $\Delta \mathbf{P}$ & $\begin{array}{l}\text { Absolute }\left(\Delta \mathbf{P}-\sum\right. \\
\text { combination) }\end{array}$ \\
\hline 1 & 1 & 0.1 & 2.6 & 2.5 & 33 & $2,3,5$ & 1.359 & 2.6 & 1.241 \\
\hline 2 & 2 & 0.196 & 2.6 & 2.404 & 34 & $2,3,6$ & 1.959 & 2.6 & 0.641 \\
\hline 3 & 3 & 0.413 & 2.6 & 2.187 & 35 & $2,4,5$ & 1.656 & 2.6 & 0.944 \\
\hline 4 & 4 & 0.71 & 2.6 & 1.89 & 36 & $2,4,6$ & 2.256 & 2.6 & 0.344 \\
\hline 5 & 5 & 0.75 & 2.6 & 1.85 & 37 & $2,5,6$ & 2.296 & 2.6 & 0.304 \\
\hline 6 & 6 & 1.35 & 2.6 & 1.25 & 38 & $3,4,5$ & 1.873 & 2.6 & 0.727 \\
\hline 7 & 1,2 & 0.296 & 2.6 & 2.304 & 39 & $3,4,6$ & 2.473 & 2.6 & 0.127 \\
\hline 8 & 1,3 & 0.513 & 2.6 & 2.087 & 40 & $3,5,6$ & 2.513 & 2.6 & 0.087 \\
\hline 9 & 1,4 & 0.81 & 2.6 & 1.79 & 41 & $4,5,6$ & 2.81 & 2.6 & 0.21 \\
\hline 10 & 1,5 & 0.85 & 2.6 & 1.75 & 42 & $1,2,3,4$ & 1.419 & 2.6 & 1.181 \\
\hline 11 & 1,6 & 1.45 & 2.6 & 1.15 & 43 & $1,2,3,5$ & 459 & 2.6 & 1.141 \\
\hline 12 & 2,3 & 0.609 & 2.6 & 1.991 & 44 & $1,2,3,6$ & 2059 & 2.6 & 0.541 \\
\hline 13 & 2,4 & 0.906 & 2.6 & 1.694 & 45 & $1,2,4,5$ & 1756 & 2.6 & 0.844 \\
\hline 14 & 2,5 & 0.946 & 2.6 & 1.654 & 46 & $1,2,4,6$ & 2356 & 2.6 & 0.244 \\
\hline 15 & 2,6 & 1.546 & 2.6 & 1.054 & 47 & $1,2,5,6$ & 2.396 & 2.6 & 0.204 \\
\hline 16 & 3,4 & 1.123 & 2.6 & 1.477 & 48 & $1,3,4,5$ & 1.973 & 2.6 & 0.627 \\
\hline 17 & 3,5 & 1.163 & 2.6 & 1.437 & 49 & $1,3,4,6$ & 2.573 & 2.6 & 0.027 \\
\hline 18 & 3,6 & 1.763 & 2.6 & 0.837 & 50 & $1,3,5,6$ & 2.613 & 2.6 & $0.01 \beta$ \\
\hline 19 & 4,5 & 1.46 & 2.6 & 1.14 & 51 & $1,4,5,6$ & 2.91 & 2.6 & 0.37 \\
\hline 20 & 4,6 & 2.06 & 2.6 & 0.54 & 52 & $2,3,4,5$ & 2.069 & 2.6 & \multirow{3}{*}{$\begin{array}{l}\text { Min } \\
\text { Diff }\end{array}$} \\
\hline 21 & 5,6 & 2.1 & 2.6 & 0.5 & 53 & $2,3,4,6$ & 2.669 & 2.6 & \\
\hline 22 & $1,2,3$ & 0.709 & 2.6 & 1.891 & 54 & $2,3,5,6$ & 2.709 & 2.6 & \\
\hline 23 & $1,2,4$ & 1.006 & 2.6 & 1.594 & 55 & $2,4,5,6$ & 3.006 & 2.6 & 0.406 \\
\hline 24 & $1,2,5$ & 1.046 & 2.6 & 1.554 & 56 & $3,4,5,6$ & 3.223 & 2.6 & 0.623 \\
\hline 25 & $1,2,6$ & 1.646 & 2.6 & 0.954 & 57 & $1,2,3,4,5$ & 2.169 & 2.6 & 0.431 \\
\hline 26 & $1,3,4$ & 1.223 & 2.6 & 1.377 & 58 & $1,2,3,4,6$ & 2.769 & 2.6 & 0.169 \\
\hline 27 & $1,3,5$ & 1.263 & 2.6 & 1.337 & 59 & $1,2,3,5,6$ & 2.809 & 2.6 & 0.209 \\
\hline 28 & $1,3,6$ & 1.863 & 2.6 & 0.737 & 60 & $1,2,4,5,6$ & 3.106 & 2.6 & 0.506 \\
\hline 29 & $1,4,5$ & 1.56 & 2.6 & 1.04 & 61 & $1,3,4,5,6$ & 3.323 & 2.6 & 0.723 \\
\hline 30 & $1,4,6$ & 2.16 & 2.6 & 0.44 & 62 & $2,3,4,5,6$ & 3.419 & 2.6 & 0.819 \\
\hline 31 & $1,5,6$ & 2.2 & 2.6 & 0.4 & 63 & $1,2,3,4,5,6$ & 3.519 & 2.6 & 0.919 \\
\hline 32 & $2,3,4$ & 1.319 & 2.6 & 1.281 & - & - & - & - & - \\
\hline
\end{tabular}

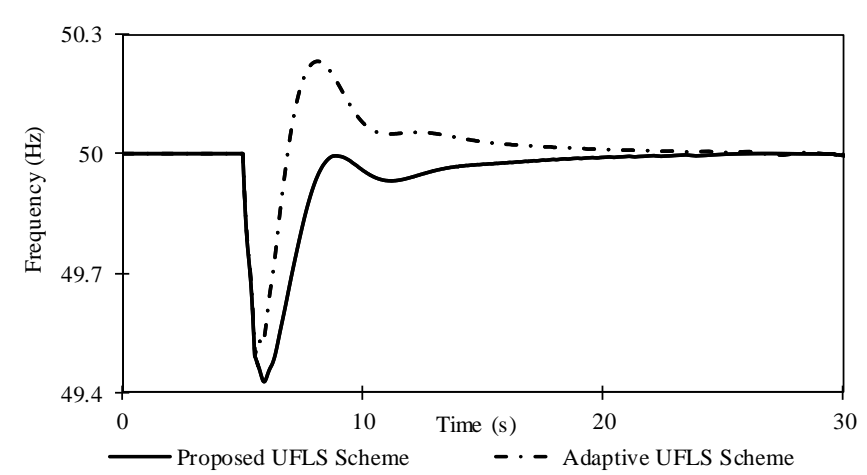

Fig. 9. Frequency response of UFLS schemes for islanding event.

It can be observed from Fig. 9 that adaptive scheme possess very high overshoot compared to proposed UFLS scheme. On the other hand, absence of overshoot in the frequency response of proposed UFLS scheme justifies that it has achieved the accurate load shedding.

The adaptive UFLS scheme has resulted in an overshoot of $50.23 \mathrm{~Hz}$. The reason for this overshoot is that an adaptive UFLS scheme has not included the spinning reserve in estimating the load shed amount. Due to this, it has resulted in shedding of extra loads. Hence, for 3.5 MW power imbalance, adaptive UFLS schemes has shed 3.519 MW load whereas, the proposed UFLS scheme has shed the $2.613 \mathrm{MW}$ due to the advantage of random priority. This accurate load shedding has caused the restoring of system frequency to its original value without overshoot. The adaptive based UFLS scheme has disconnected the first 6 loads whereas the proposed UFLS scheme has disconnected $1^{\text {st }}, 3^{\text {rd }}, 5^{\text {th }}$ and $6^{\text {th }}$ loads only. Thus, addition of random priority to few loads can provide flexibility to achieve accurate load shedding.

TABLE III. UFLS PARAMETERS FOR ISLANDING EVENT

\begin{tabular}{|l|l|l|}
\hline Parameter & $\begin{array}{l}\text { Adaptive UFLS } \\
\text { scheme }\end{array}$ & Proposed UFLS scheme \\
\hline Power Imbalance & $3.5 \mathrm{MW}$ & $3.5 \mathrm{MW}$ \\
\hline Total load shed & $3.519 \mathrm{MW}$ & $2.613 \mathrm{MW}$ \\
\hline $\begin{array}{l}\text { Loads } \\
\text { Disconnected }\end{array}$ & Load1-Load6 & Load1,Load3, Load5-Load6 \\
\hline $\begin{array}{l}\text { Frequency } \\
\text { Undershoot }\end{array}$ & $49.494 \mathrm{~Hz}$ & $49.43 \mathrm{~Hz}$ \\
\hline $\begin{array}{l}\text { Frequency } \\
\text { Overshoot }\end{array}$ & $50.23 \mathrm{~Hz}$ & - \\
\hline
\end{tabular}




\section{B. For Load Increament}

This case is simulated for load increment scenario when the system is operating in islanded mode. For this case, an addition of $1.5 \mathrm{MW}$ load at Bus 10 is simulated at $\mathrm{t}=5 \mathrm{~s}$. Upon addition of this load, FLSAEM checks first frequency limit of $49.5 \mathrm{~Hz}$. After checking this, FLSAEM using frequency and rate of change of frequency measurements, estimates the load shed amount for this case and sends this amount to ALSM module. For a $1.5 \mathrm{MW}$ load increment, the FLSAEM module determines 0.6 MW as the load shed amount. The frequency response of both UFLS schemes is shown in Fig. 10, whereas power imbalance, total amount of load shed, and other parameters of all these schemes are shown in Table IV.

TABLE IV. UFLS PARAMETERS FOR LOAD INCREMENT CASE

\begin{tabular}{|l|l|l|}
\hline Parameter & $\begin{array}{l}\text { Adaptive UFLS } \\
\text { scheme }\end{array}$ & $\begin{array}{l}\text { Proposed UFLS } \\
\text { scheme }\end{array}$ \\
\hline Power Imbalance & $1.5 \mathrm{MW}$ & $1.5 \mathrm{MW}$ \\
\hline Total load shed & $2.142 \mathrm{MW}$ & $0.609 \mathrm{MW}$ \\
\hline Loads Disconnected & Load1-Load5 & Load2, Load3 \\
\hline $\begin{array}{l}\text { Frequency } \\
\text { Undershoot }\end{array}$ & $49.499 \mathrm{~Hz}$ & $49.482 \mathrm{~Hz}$ \\
\hline $\begin{array}{l}\text { Frequency } \\
\text { Overshoot }\end{array}$ & $50.24 \mathrm{~Hz}$ & - \\
\hline
\end{tabular}

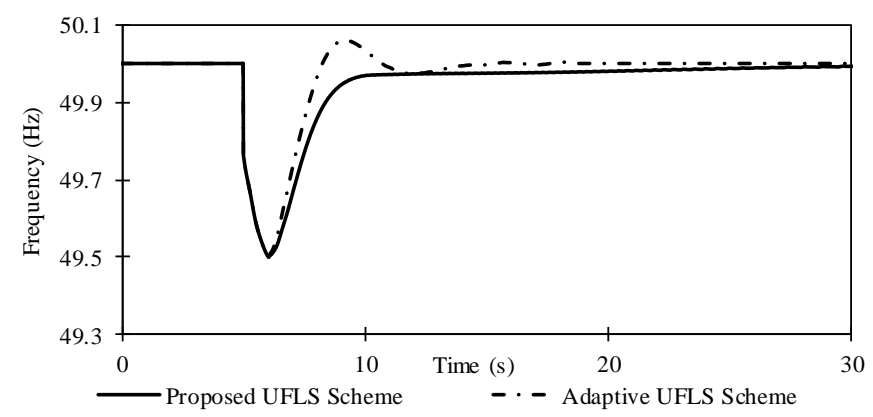

Fig. 10. Frequency response of UFLS schemes for load increment case.

It can be noticed from the Fig. 7 and Table IV that the adaptive UFLS scheme has very high overshoot compared to proposed UFLS scheme. The adaptive UFLS scheme has resulted in an overshoot of $50.24 \mathrm{~Hz}$. The reason for this overshoot is that an adaptive UFLS scheme has not included the spinning reserve in estimating the load shed amount that has resulted in shedding of extra loads. However, the proposed UFLS scheme because of random load priority has disconnected 0.609 MW load.

The frequency response of the proposed UFLS scheme restores to its original value without overshoot. The adaptive UFLS scheme has disconnected the loads up to $5^{\text {th }}$ ranked whereas the proposed UFLS scheme has disconnected $2^{\text {nd }}$ and $3^{\text {rd }}$ ranked loads only. This accurate load shedding has caused the restoring of system frequency to its original value without overshoot.

\section{DISCUSSIONS}

From the simulation results, it can be observed that proposed UFLS scheme based on combination of random and fixed load priority provides flexibility that leads to accurate load shedding. The response of the proposed UFLS scheme has been compared with adaptive based UFLS scheme in terms of load amount shed, frequency undershoot and overshoot for different scenarios of islanding event, and load increment case. The simulation results of adaptive UFLS scheme have shown that despite of the accurate estimation of power imbalance, adaptive UFLS scheme is not succeeded to achieve accurate load shedding. This happened due to fixed load priority, and inability to consider the spinning reserve in estimation of load shed amount. Furthermore, the adaptive UFLS scheme possessed very high overshoot, disconnected higher amount of load compared to proposed UFLS scheme. On the other hand, the performance of proposed UFLS scheme in all cases has shown that it has smaller undershoot, shed lesser loads compared to adaptive UFLS scheme. In proposed UFLS scheme performance, the restoring of system frequency to its original value without overshoot has justified that the proposed scheme has achieved the accurate load shedding. Hence, it can be concluded that providing random load priority in few loads of the distribution system can assist the UFLS scheme to obtain accurate amount of load shedding. The proposed technique considers only six random loads. However, in future, some optimization techniques may be used to overcome this limitation of random load priority. It is necessary because power system may contain large number of loads and the performance of the proposed technique can be improved by overcoming this limitation.

\section{CONCLUSION AND FUTURE WORK}

This research has proposed a new smart under frequency load shedding (UFLS) scheme to enable successfully the intentional islanding operation of distribution system connected with distributed generation. The proposed UFLS scheme was mainly consisted of fuzzy load shed amount estimation module (FLSAEM) and accurate load shedding module (ALSM). The FLSAEM used Takagi-Sugeno fuzzy inference system to estimate the accurate load shed amount and ALSM perform the accurate load shedding based on flexible load priority. The performance of the proposed UFLS scheme is validated for islanding event, and load increment case. To further highlight the advantages of proposed UFLS schemes, its response has been compared with adaptive UFLS scheme. The simulation results have shown that the proposed UFLS scheme has achieved the accurate load shedding due to advantage of flexible priority whereas adaptive UFLS scheme due to inaccurate estimation and fixed load priority have not succeeded to achieve accurate load shedding. Thus, it has been proved that load priority plays an important role in accurate amount of load shedding. In future, for smart grid, this factor should also be considered in order to achieve enhanced accuracy of the under frequency load shedding schemes. In the future work, an optimization technique will be used to consider large number of random priority loads in order to enhance the capability of the proposed technique for large power system.

\section{REFERENCES}

[1] M. Silva, H. Morais, and Z. Vale, "An integrated approach for distributed energy resource short-term scheduling in smart grids considering realistic power system simulation," Energy Conversion and Management, vol. 64, pp. 273-288, 2012.

[2] V. L. Merlin, R. C. Santos, A. P. Grilo, J. C. M. Vieira, D. V. Coury, and M. Oleskovicz, "A new artificial neural network based method for 
islanding detection of distributed generators," International Journal of Electrical Power \& Energy Systems, vol. 75, pp. 139-151, 2// 2016.

[3] P. A. Gooding, E. Makram, and R. Hadidi, "Probability analysis of distributed generation for island scenarios utilizing Carolinas data," Electric Power Systems Research, vol. 107, pp. 125-132, 2014.

[4] J. A. Laghari, H. Mokhlis, A. H. Abu Bakar, and H. Mohamad, "A fuzzy based load frequency control for distribution network connected with mini hydro power plant," Journal of Intelligent \& Fuzzy Systems, vol. 26, pp. 1301-1310, 2014.

[5] IEEE Std 1547, "IEEE Standard for Interconnecting Distributed Resources With Electric Power Systems," IEEE Std 1547-2003, pp. 0_116, 2003.

[6] IEEE Std 929, "IEEE Recommended Practice for Utility Interface of Photovoltaic (PV) Systems," IEEE Std 929-2000, p. i, 2000.

[7] J. A. Laghari, H. Mokhlis, M. Karimi, A. H. A. Bakar, and H. Mohamad, "Computational Intelligence based techniques for islanding detection of distributed generation in distribution network: A review," Energy Conversion and Management, vol. 88, pp. 139-152, 2014.

[8] H. Samet and M. Rashidi, "Coordinated under frequency load and capacitor shedding for bulk power systems," Generation, Transmission \& Distribution, IET, vol. 7, pp. 799-812, 2013.

[9] M. D. Maram and N. Amjady, "Event-based remedial action scheme against super-component contingencies to avert frequency and voltage instabilities," Generation, Transmission \& Distribution, IET, vol. 8, pp. 1591-1603, 2014.

[10] Y. Dai, Y. Xu, Z. Y. Dong, K. P. Wong, and L. Zhuang, "Real-time prediction of event-driven load shedding for frequency stability enhancement of power systems," Generation, Transmission \& Distribution, IET, vol. 6, pp. 914-921, 2012.

[11] U. Rudez and R. Mihalic, "Predictive underfrequency load shedding scheme for islanded power systems with renewable generation," Electric Power Systems Research, vol. 126, pp. 21-28, 2015.

[12] U. Rudez and R. Mihalic, "Analysis of Underfrequency Load Shedding Using a Frequency Gradient," Power Delivery, IEEE Transactions on, vol. 26, pp. 565-575, 2011.

[13] J. A. Laghari, H. Mokhlis, A. H. A. Bakar, and H. Mohamad, "Application of computational intelligence techniques for load shedding in power systems: A review," Energy Conversion and Management, vol. 75, pp. 130-140, 2013.

[14] U. Rudez and R. Mihalic, "A novel approach to underfrequency load shedding," Electric Power Systems Research, vol. 81, pp. 636-643, 2011.

[15] W. Gu, W. Liu, C. Shen, and Z. Wu, "Multi-stage underfrequency load shedding for islanded microgrid with equivalent inertia constant analysis," International Journal of Electrical Power \& Energy Systems, vol. 46, pp. 36-39, 2013.

[16] P. Mahat, C. Zhe, and B. Bak-Jensen, "Underfrequency Load Shedding for an Islanded Distribution System With Distributed Generators," IEEE Transactions on Power Delivery, vol. 25, pp. 911-918, 2010.

[17] A. A. M. Zin, H. M. Hafiz, and W. K. Wong, "Static and dynamic under-frequency load shedding: a comparison," in Power System Technology, 2004. PowerCon 2004. 2004 International Conference on, 2004, pp. 941-945 Vol.1.

[18] F. Ceja-Gomez, S. S. Qadri, and F. D. Galiana, "Under-Frequency Load Shedding Via Integer Programming," Power Systems, IEEE Transactions on, vol. 27, pp. 1387-1394, 2012.

[19] H. Ying-Yi and W. Shih-Fan, "Multiobjective Underfrequency Load Shedding in an Autonomous System Using Hierarchical Genetic Algorithms," IEEE Transactions on Power Delivery, vol. 25, pp. 1355$1362,2010$.

[20] E. J. Thalassinakis, E. N. Dialynas, and D. Agoris, "Method Combining ANNs and Monte Carlo Simulation for the Selection of the Load Shedding Protection Strategies in Autonomous Power Systems," IEEE Transactions on Power Systems, vol. 21, pp. 1574-1582, 2006.

[21] C.-T. Hsu, H.-J. Chuang, and C.-S. Chen, "Adaptive load shedding for an industrial petroleum cogeneration system," Expert Systems with Applications, vol. 38, pp. 13967-13974, 2011.

[22] M. A. Mitchell, J. A. P. Lopes, J. N. Fidalgo, and J. D. McCalley, "Using a neural network to predict the dynamic frequency response of a power system to an under-frequency load shedding scenario," in IEEE Power Engineering Society Summer Meeting, 2000, pp. 346-351 vol. 1.

[23] H. Mokhlis, J. A. Laghari, A. H. A. Bakar, and M. Karimi, "A Fuzzy Based Under-Frequency Load Shedding Scheme for Islanded Distribution Network Connected With DG," International Review of Electrical Engineering (I.R.E.E), vol. 7, 2012.

[24] V. V. Terzija, "Adaptive underfrequency load shedding based on the magnitude of the disturbance estimation," IEEE Transactions on Power Systems, vol. 21, pp. 1260-1266, 2006.

[25] A. A. Mohd Zin, H. Mohd Hafiz, and M. S. Aziz, "A review of underfrequency load shedding scheme on TNB system," in Power and Energy Conference, PECon 2004. Proceedings. National, pp. 170-174. 